\title{
Classification and pharmacological treatment of preschool wheezing: changes since 2008
}

\author{
Paul L.P. Brand ${ }^{1,2}$, Daan Caudri ${ }^{3}$, Ernst Eber ${ }^{4}$, Erol A. Gaillard ${ }^{5}$, \\ Luis Garcia-Marcos ${ }^{6}$, Gunilla Hedlin ${ }^{7}$, John Henderson ${ }^{8}$, Claudia E. Kuehni ${ }^{9}$, \\ Peter J.F.M. Merkus ${ }^{10}$, Soren Pedersen ${ }^{11}$, Arunas Valiulis ${ }^{12}$, Göran Wennergren ${ }^{13}$ \\ and Andrew Bush ${ }^{14}$
}

\begin{abstract}
Affiliations: 'Princess Amalia Children's Centre, Isala Hospital, Zwolle, ${ }^{2}$ UMCG Postgraduate School of Medicine, University Medical Centre and University of Groningen, Groningen, ${ }^{3}$ Dept of Pediatrics/Respiratory Medicine, Erasmus University Medical Center - Sophia Children's Hospital, Rotterdam, and ${ }^{10}$ Dept of Pediatrics, division of Respiratory Medicine, Radboud University Medical Center, Nijmegen, the Netherlands. ${ }^{4}$ Respiratory and Allergic Disease Division, Dept of Paediatrics and Adolescence Medicine, Medical University of Graz, Graz, Austria. ${ }^{5}$ Institute for Lung Health, NIHR Respiratory Biomedical Research Unit, Dept of Infection, Immunity and Inflammation, University of Leicester, Leicester, ${ }^{8}$ School of Social and Community Medicine, University of Bristol, Bristol, and ${ }^{14}$ Imperial College and Royal Brompton Hospital, London, UK. ${ }^{6}$ Dept of Pediatrics, Division of Allergology and Pulmonology, Virgen de la Arrixaca University Children's Hospital, University of Murcia, Murcia, Spain. 'Dept of Women's and Children's Health and Centre for Allergy Research, Karolinska Institutet, Stockholm, and ${ }^{13}$ Dept of Pediatrics, University of Gothenburg, Queen Silvia Children's Hospital, Gothenburg, Sweden. ${ }^{9}$ Institute of Social and Preventive Medicine, University of Bern, Bern, Switzerland. ${ }^{11}$ University of Southern Denmark, Paediatric Research Unit, Kolding Hospital, Kolding, Denmark. ${ }^{12}$ Vilnius University Clinic of Children's Diseases, Vilnius, Lithuania.
\end{abstract}

Correspondence: P.L.P. Brand, Princess Amalia Children's Centre, Isala Hospital, PO Box 10400, 8000 GK Zwolle, the Netherlands. E-mail: p.l.p.branddisala.nl

ABSTRACT Since the publication of the European Respiratory Society Task Force report in 2008, significant new evidence has become available on the classification and management of preschool wheezing disorders. In this report, an international consensus group reviews this new evidence and proposes some modifications to the recommendations made in 2008. Specifically, the consensus group acknowledges that wheeze patterns in young children vary over time and with treatment, rendering the distinction between episodic viral wheeze and multiple-trigger wheeze unclear in many patients. Inhaled corticosteroids remain first-line treatment for multiple-trigger wheeze, but may also be considered in patients with episodic viral wheeze with frequent or severe episodes, or when the clinician suspects that interval symptoms are being under reported. Any controller therapy should be viewed as a treatment trial, with scheduled close followup to monitor treatment effect. The group recommends discontinuing treatment if there is no benefit and taking favourable natural history into account when making decisions about long-term therapy. Oral corticosteroids are not indicated in mild-to-moderate acute wheeze episodes and should be reserved for severe exacerbations in hospitalised patients. Future research should focus on better clinical and genetic markers, as well as biomarkers, of disease severity.

@ERSpublications

The distinction between episodic viral and multiple-trigger wheeze is unclear in many preschool children http://ow.ly/sKYZF

Received: Nov 152013 | Accepted after revision: Jan 10 2014 | First published online: Feb 132014

Support statement: A. Bush was supported by the NIHR Respiratory Disease Biomedical Research Unit at the Royal Brompton and Harefield NHS Foundation Trust and Imperial College London.

Conflict of interest: Disclosures can be found alongside the online version of this article at www.erj.ersjournals.com

Copyright @ERS 2014 


\section{Introduction}

Wheezing and shortness of breath in preschool children are among the most common presenting symptoms in paediatric practice. Approximately one in three children has at least one episode of wheeze before their third birthday $[1,2]$. Parents vary considerably in their understanding of the term "wheeze" [3] but wheeze confirmed by a doctor is associated with lower airway obstruction [4]. Even among such children with doctor-confirmed wheeze, considerable clinical heterogeneity exists (table 1).

Due to this heterogeneity, and despite its common occurrence, relatively little evidence is available on the pathophysiology and treatment of wheezing in preschool children [9]. Many preschool children with wheeze become symptom-free between the ages of 3 and 8 years $[1,2,10,11]$. This distinguishes preschool wheeze from the more persistent asthma in later childhood and adulthood, and illustrates the heterogeneity of wheeze in this age group. Until recently, however, international asthma management guidelines did not provide separate recommendations for preschool children. In 2008, a European Respiratory Society (ERS) Task Force published a report on the classification, diagnosis and management of preschool wheeze, based on a systematic and structured assessment of the literature available at that point in time [8]. One of the Task Force's main findings was that "the evidence on which to base recommendations is limited" and that "The present recommendations are likely to change when more evidence becomes available." The Task Force recommended distinguishing between two phenotypes based on temporal patterns of wheeze and proposed a differentiated approach to controller therapy (table 2) [8].

The ERS Task Force report has been widely cited (over 375 citations on October 1, 2013) and used. Despite the report's care in outlining the limitations of the available evidence, the distinction between episodic viral wheeze (EVW) and multiple-trigger wheeze (MTW) has gained widespread acceptance in patient care [12, 13]. Meanwhile, however, concerns have been raised on the validity and usefulness of this phenotype classification. First, the distinction between EVW and MTW does not take severity or frequency of episodes into account. In clinical practice, however, these play a major role in deciding which affected children are prescribed daily controller therapy, although the evidence that any controller therapy affects the frequency or severity of wheeze with viral colds in preschool children is scant [5]. Second, it has been argued that the distinction between EVW and MTW is more a marker of disease severity than of different clinical phenotypes [14]. Results from several other studies, reviewed here, also suggest that the ERS Task Force report's classification system and treatment recommendations should be reconsidered. Because of this, an international group of experts convened at the 2013 ERS Annual Congress to discuss the current state of the art of the classification and management of preschool wheeze, and to formulate a consensus statement on the current value of phenotyping preschool wheezing disorders into EVW and MTW, and the treatment approach associated with it. This article provides a summary of this consensus meeting (table 3 ).

\section{Distinguishing between EVW and MTW}

The group agreed that the distinction between EVW and MTW is not as clear-cut as the 2008 report may have suggested, and that it changes over time in many children [15]. Despite significant differences in clinical presentation, lung function and genetics between children with EVW and MTW phenotypes, there is a large overlap between the groups [16-19]. While some children retain a consistent pattern of EVW or MTW over longer periods, symptom patterns change over time in many [15]. The underlying airway pathology remains unclear in many preschool children with recurrent troublesome wheeze and this hinders the choice of the most effective controller therapy. The group agreed that wheeze in preschool children is probably the final common pathway of a range of pathophysiological mechanisms involving numerous risk factors and that it is impossible to break the patients down into mutually exclusive subgroups that remain consistent over time. While at the extremes, the differences between the phenotypes of EVW and MTW are clear-cut, in many cases, they are quantitative rather than qualitative.

The group agreed that the temporal pattern of wheeze during preschool years (EVW or MTW) is a relatively poor predictor of long-term outcome (transient versus persistent wheeze). Frequency and severity of wheezing episodes are stronger predictors of long-term outcome [11]. The majority of children with troublesome EVW referred to a secondary care clinic remained symptomatic at the age of 5-10 years and a number of these children had developed symptoms between episodes characteristic of MTW [20].

\section{TABLE 1 Preschool children with wheeze differ in their characteristics}

Frequency of episodes

Severity of episodes

Temporal pattern

Long-term outcome of symptoms
Most children wheeze occasionally, some have frequent episodes $[5,6]$ Ranging from very mild to severe and life-threatening $[5,7]$

Only wheezing with viral colds or in response to other triggers $[6,8]$ Transient versus persistent wheeze [1, 2] 
TABLE 2 Distinction between temporal patterns of preschool wheeze and recommendations for controller therapy, as issued in the European Respiratory Society 2008 Task Force report [8]

Phenotype

Temporal pattern

Proposed first choice of controller therapy

Episodic viral wheeze

Multiple-trigger wheeze
Wheezing during discrete time periods, often in association with clinical evidence of a viral cold, with absence of wheeze between episodes Wheezing that shows discrete exacerbations (as with episodic viral wheeze) but also symptoms between episodes
Montelukast

Inhaled corticosteroids

In addition, some group members felt that parents may under-report interval symptoms in preschool children because the symptoms during viral episodes are most troublesome, and viral episodes may persist for weeks and recur rapidly in autumn and winter.

\section{Indications for and choice of controller therapy}

The group agreed that the two main reasons for starting any controller therapy in preschool children with wheeze were frequent symptoms (on most days of the week, responding to $\beta_{2}$-agonists) or frequent and severe acute episodes. There was consensus that the current state of the evidence does not allow a clear-cut distinction between children who will respond to inhaled corticosteroids (ICS), to montelukast or to neither treatment. A trial performed in the 1990s in preschool children with only EVW did not show a beneficial effect of ICS on frequency and severity of episodes [21]. A more recent systematic review of randomised controlled trials showed that ICS are effective in reducing frequency of preschool wheeze episodes when trials are pooled irrespective of phenotype [22]. However, because data on wheeze phenotype were lacking in most studies, the review could neither confirm nor exclude a differential response to ICS in EVW or MTW. Atopy did not predict the response to ICS in this meta-analysis [22]. A recent report showed that the degree of asthma control achieved in 2-6 year old children was most strongly determined by their adherence to ICS treatment [23]. The lack of data on the symptom pattern in this study does not allow a firm conclusion whether this applies to both EVW and MTW. Two randomised trials compared the effect

TABLE 32013 consensus statement on classification and management of preschool wheezing disorders

\section{Distinction of preschool wheeze phenotypes}

\section{Daily controller therapy}

Treatment of acute episodes
The distinction between EVW and MTW is not clear in all patients Some children retain a consistent pattern of EVW or MTW, but symptom patterns change over time in many patients and their airway pathology remains unclear

Severity and frequency of episodes seem to be at least as important to distinguish between children as the distinction between EVW and MTW In children with MTW, ICS are the first choice for daily controller therapy In children with EVW, daily therapy may be considered with either ICS or montelukast if:

the attacks are severe (requiring hospital admission or systemic corticosteroids); or

the attacks are frequent; or

the clinician suspects that interval symptoms are being under reported

Any controller therapy should be viewed as a treatment trial, with scheduled follow-up

Discontinue treatment if there has been no benefit

Take favourable natural history into account: taper down to lowest effective dose, and discontinue treatment if the child has been symptom-free for 3 months on low-dose therapy

Oral corticosteroids are not indicated in preschool children with an exacerbation of viral wheeze who do not need to be admitted to hospital

Oral corticosteroids are indicated only in preschool children admitted to hospital with very severe wheeze; even in this group, evidence to support the use of prednisolone is not robust 
on day-to-day symptoms and exacerbation frequency of daily low-dose and intermittent high-dose nebulised ICS [24, 25]. Interval symptoms decreased more with continuous low-dose treatment in one study [25] but there was no difference in the number and severity of exacerbations in either study [24, 25]. Both studies used nebulised treatment, which is more cumbersome and less effective than a metered-dose inhaler (MDI)/spacer combination [26]. In direct comparisons, ICS are more effective than montelukast [27]. Only one such comparative trial has been performed in preschool children, in which budesonide was more effective in reducing wheeze exacerbations requiring oral corticosteroids than montelukast [28].

Based on these findings, a number of current guidelines do not distinguish between wheeze phenotypes. Using GRADE (Grading of Recommendations Assessment, Development and Evaluation) methodology, the Dutch Paediatric Respiratory Society recently recommended using ICS as the first choice of maintenance treatment in all preschool children, irrespective of phenotype [29]. A similar recommendation was issued by GINA (Global Initiative for Asthma) [30]. The British Thoracic Society guideline also does not provide a phenotype-directed treatment recommendation for preschool children with recurrent wheeze [31].

In preschool children, both montelukast and ICS are usually well tolerated with few side effects. Recent evidence suggests significant behavioural problems as a side-effect of montelukast in a small proportion of young children with wheeze [32]. This has also been described in case reports of children using ICS [33] but this side-effect appears to be very rare in preschool children [34]. Concerns remain, however, over the effects of ICS on height growth. Therapy with ICS is associated with a $0.5-1-\mathrm{cm}$ reduction in height growth during the first year of treatment [35]. Although this effect does not accumulate after longer follow-up, the increased risk of this systemic side effect in the youngest children calls for caution in prescribing ICS to young children with wheeze [36]. ICS, while effective in reducing (in particular, interval) symptoms, do not change the long-term course or persistence of the disease [35, 37].

Based on these considerations, the group agreed that the decision to start maintenance treatment is primarily determined by the severity and frequency of wheeze episodes. There was consensus that ICS are the first-choice maintenance therapy for MTW. In EVW, either ICS or montelukast may be prescribed. Any treatment given should be viewed as a therapeutic trial; regular scheduled follow-up is essential to review the response to treatment. If there is no benefit of the controller therapy started after $2-3$ months, it should be discontinued and the child investigated further. If symptoms resolve during controller therapy, this may be due either to an effect of treatment or to the favourable natural history of preschool wheezing. This can only be distinguished by withdrawing treatment after the child has become symptom free and to restart treatment only if symptoms recur.

\section{Treatment of acute exacerbations of wheeze}

Inhaled bronchodilators remain the treatment of choice for symptoms of wheeze and shortness of breath in young children, although the evidence supporting their usefulness is limited [38]. A large and well-designed randomised controlled trial in children aged 10 months to 6 years with acute virus-induced wheeze showed no beneficial effect of a 5-day course of 10-20 mg oral prednisolone once a day on duration and severity of symptoms [39]. Similarly, a course of oral corticosteroids started at home by parents was ineffective in reducing the burden or duration of acute wheeze in preschool children [40]. Although these studies used a relatively low dose of prednisolone and included many children with mild symptoms, the results call for restraint in the use of systemic corticosteroids in the treatment of acute exacerbations of wheeze in this age group. Pre-emptive use of high-dose ICS (fluticasone $1500 \mu \mathrm{g}$ per day), although effective in reducing severity of wheeze exacerbations, did not reduce acute care visits or hospital admissions and was associated with growth reduction [41].

Based on the available evidence, the group reached the consensus that the large majority of preschool children with an acute exacerbation of wheeze can be treated with only inhaled bronchodilators. The group also agreed not to treat children who do not require hospitalisation with systemic corticosteroids, and to limit the use of prednisolone in hospitalised patients to those with very severe wheeze and dyspnoea, requiring frequent inhalations and supplemental oxygen or respiratory support.

\section{Future priorities}

The consensus group discussed priorities for further research and agreed on the following (table 4). Ongoing research efforts are needed to improve our understanding of the nature and underlying mechanisms of wheeze in preschool children [9]. This can best be achieved by collecting high-quality data on a large number of patient characteristics, including symptom pattern and severity, atopic sensitisation and other allergic disease, family history of both atopy and respiratory symptoms, and environmental exposures such as indoor allergens, tobacco smoke exposure and traffic air pollution [42]. In addition, better biomarkers of treatment response (including but not limited to genetic studies) are needed [42]. 


\section{TABLE 4 Priorities for future research}

Better genetic and biomarkers of response to (controller and symptomatic) treatment

More RCTs of (controller) treatment using clearly characterised groups of patients, including but not limited to:

Symptom pattern and severity

Atopic sensitisation and presence of allergic disease

Family history of atopy, asthma and wheezing

Environmental exposures such as indoor allergens, tobacco smoke exposure and traffic air pollution; planned subgroup analyses of treatment response in RCTs based on the same variables or on prediction indices

Development and validation of better ways to assess symptoms, impact on the child's daily activities and the parental perception of these symptoms

$\mathrm{RCT}$ : randomised controlled trial.

We need better ways to assess and record (parental perception of) symptoms in young children. Finally, the group felt that well-designed trials are needed to study the effect of continuous ICS treatment delivered by $\mathrm{MDI} / \mathrm{spacer}$ combination on the frequency and severity of acute episodes in preschool children with recurrent wheeze, and to analyse whether treatment response varies by wheeze phenotype (using different definitions), symptom pattern, severity, genotype, other characteristics or combinations of such variables (predictive indices) [11, 43].

\section{Conclusions and implications for practice}

Wheeze patterns in young children vary over time and with treatment. The decision to start any controller therapy is most strongly determined by the pattern, frequency and severity of symptoms. Any preschool child with troublesome recurrent wheeze could be started on either ICS or montelukast. The consensus group agrees that all children using controller therapy must be reviewed regularly to evaluate the response to treatment and any changes in symptom pattern. Atopy does not predict the response to controller therapy. Oral prednisolone is not required in the large majority of preschool children with an acute wheeze exacerbation and should be reserved for those with most severe symptoms. The evidence base for understanding the pathophysiology and treatment of preschool wheezing is still limited. Therefore, additional high-quality studies with a clear and comprehensive description of study subjects are needed.

\section{References}

Martinez FD, Wright AL, Taussig LM, et al. Asthma and wheezing in the first six years of life. N Engl J Med 1995; 332: $133-138$

2 Henderson J, Granell R, Heron J, et al. Associations of wheezing phenotypes in the first 6 years of life with atopy, lung function and airway responsiveness in mid-childhood. Thorax 2008; 63: 974-980.

3 Cane RS, Ranganathan SC, McKenzie SA. What do parents of wheezy children understand by "wheeze"? Arch Dis Child 2000; 82: 327-332.

4 Lowe L, Murray CS, Martin L, et al. Reported versus confirmed wheeze and lung function in early life. Arch Dis Child 2004; 89: 540-543.

5 Schultz A, Brand PL. Episodic viral wheeze and multiple trigger wheeze in preschool children: a useful distinction for clinicians? Paediatr Respir Rev 2011; 12: 160-164

6 Kuehni CE, Davis A, Brooke AM, et al. Are all wheezing disorders in very young (preschool) children increasing in prevalence? Lancet 2001; 357: 1821-1825.

7 Bacharier LB, Phillips BR, Bloomberg GR, et al. Severe intermittent wheezing in preschool children: a distinct phenotype. J Allergy Clin Immunol 2007; 119: 604-610.

8 Brand PL, Baraldi E, Bisgaard H, et al. Definition, assessment and treatment of wheezing disorders in preschool children: an evidence-based approach. Eur Respir J 2008; 32: 1096-1110.

9 Spycher BD, Silverman M, Kuehni CE. Phenotypes of childhood asthma: are they real? Clin Exp Allergy 2010; 40: $1130-1141$.

10 Savenije OE, Kerkhof M, Koppelman GH, et al. Predicting who will have asthma at school age among preschool children. J Allergy Clin Immunol 2012; 130: 325-331.

11 Pescatore AM, Dogaru CM, Duembgen L, et al. A simple asthma prediction tool for preschool children with wheeze or cough. J Allergy Clin Immunol 2014; 133: 111-118.

12 Bhatt JM, Smyth AR. The management of pre-school wheeze. Paediatr Respir Rev 2011; 12: 70-77.

13 Davies BR, Carroll WD. The use of inhaled corticosteroids in the wheezy under 5-year-old child. Arch Dis Child Educ Pract Ed 2011; 96: 61-66.

14 Garcia-Marcos L, Martinez FD. Multitrigger versus episodic wheeze in toddlers: New phenotypes or severity markers? J Allergy Clin Immunol 2010; 126: 489-490.

15 Schultz A, Devadason SG, Savenije OE, et al. The transient value of classifying preschool wheeze into episodic viral wheeze and multiple trigger wheeze. Acta Paediatr 2010; 99: 56-60.

16 Granell R, Henderson AJ, Timpson N, et al. Examination of the relationship between variation at 17q21 and childhood wheeze phenotypes. J Allergy Clin Immunol 2013; 131: 685-694.

17 Sonnappa S, Bastardo CM, Wade A, et al. Symptom-pattern phenotype and pulmonary function in preschool wheezers. J Allergy Clin Immunol 2010; 126: 519-526. 
18 Sonnappa S, Bastardo CM, Saglani S, et al. Relationship between past airway pathology and current lung function in preschool wheezers. Eur Respir J 2011; 38: 1431-1436.

19 Goksor E, Alm B, Thengilsdottir H, et al. Preschool wheeze - impact of early fish introduction and neonatal antibiotics. Acta Paediatr 2011; 100: 1561-1566.

20 Kappelle L, Brand PL. Severe episodic viral wheeze in preschool children: High risk of asthma at age 5-10 years. Eur J Pediatr 2012; 171: 947-954.

21 Wilson N, Sloper K, Silverman M. Effect of continuous treatment with topical corticosteroid on episodic viral wheeze in preschool children. Arch Dis Child 1995; 72: 317-320.

22 Castro-Rodriguez JA, Rodrigo GJ. Efficacy of inhaled corticosteroids in infants and preschoolers with recurrent wheezing and asthma: a systematic review with meta-analysis. Pediatrics 2009; 123: e519-e525.

23 Klok T, Kaptein AA, Duiverman EJ, et al. It's the adherence, stupid (that determines asthma control in preschool children)! Eur Respir J 2013 [In press DOI: 10.1183/09031936.00054613].

24 Zeiger RS, Mauger D, Bacharier LB, et al. Daily or intermittent budesonide in preschool children with recurrent wheezing. N Engl J Med 2011; 365: 1990-2001.

25 Papi A, Nicolini G, Baraldi E, et al. Regular vs prn nebulized treatment in wheeze preschool children. Allergy 2009; 64: 1463-1471.

26 Castro-Rodriguez JA, Rodrigo GJ. $\beta$-agonists through metered-dose inhaler with valved holding chamber versus nebulizer for acute exacerbation of wheezing or asthma in children under 5 years of age: a systematic review with meta-analysis. J Pediatr 2004; 145: 172-177.

27 Chauhan BF, Ducharme FM. Anti-leukotriene agents compared to inhaled corticosteroids in the management of recurrent and/or chronic asthma in adults and children. Cochrane Database Syst Rev 2012; 5: CD002314.

28 Szefler SJ, Baker JW, Uryniak T, et al. Comparative study of budesonide inhalation suspension and montelukast in young children with mild persistent asthma. J Allergy Clin Immunol 2007; 120: 1043-1050.

29 Boluyt N, Rottier BL, de Jongste JC, et al. Assessment of controversial pediatric asthma management options using GRADE. Pediatrics 2012; 130: e658-e668.

30 Pedersen SE, Hurd SS, Lemanske RF Jr, et al. Global strategy for the diagnosis and management of asthma in children 5 years and younger. Pediatr Pulmonol 2011; 46: 1-17.

31 British Thoracic Society., Scottish Intercollegiate Guidelines Network. British guideline on the management of asthma. Thorax 2008; 63: 1-121.

32 Bygdell M, Brunlof G, Wallerstedt SM, et al. Psychiatric adverse drug reactions reported during a 10-year period in the Swedish pediatric population. Pharmacoepidemiol Drug Saf 2012; 21: 79-86.

33 Connett G, Lenney W. Inhaled budesonide and behavioural disturbances. Lancet 1991; 338: 634-635.

34 Quak W, Klok T, Kaptein AA, et al. Preschool children with high adherence to inhaled corticosteroids for asthma do not show behavioural problems. Acta Paediatr 2012; 101: 1156-1160.

35 Guilbert TW, Morgan WJ, Zeiger RS, et al. Long-term inhaled corticosteroids in preschool children at high risk for asthma. N Engl J Med 2006; 354: 1985-1997.

36 Guilbert TW, Mauger DT, Allen DB, et al. Growth of preschool children at high risk for asthma 2 years after discontinuation of fluticasone. J Allergy Clin Immunol 2011; 128: 956-963.

37 Murray CS, Woodcock A, Langley SJ, et al. Secondary prevention of asthma by the use of Inhaled Fluticasone propionate in Wheezy INfants (IFWIN): double-blind, randomised, controlled study. Lancet 2006; 368: 754-762.

38 Carroll WD, Srinivas J. Bronchodilators in wheezy under 2-year-olds: when and which (if any)? Arch Dis Child Educ Pract Ed 2013; 98: 113-118.

39 Panickar J, Lakhanpaul M, Lambert PC, et al. Oral prednisolone for preschool children with acute virus-induced wheezing. N Engl J Med 2009; 360: 329-338.

40 Oommen A, Lambert PC, Grigg J. Efficacy of a short course of parent-initiated oral prednisolone for viral wheeze in children aged 1-5 years: randomised controlled trial. Lancet 2003; 362: 1433-1438.

41 Ducharme FM, Lemire C, Noya FJ, et al. Preemptive use of high-dose fluticasone for virus-induced wheezing in young children. N Engl J Med 2009; 360: 339-353.

42 Bel EH, Sousa A, Fleming L, et al. Diagnosis and definition of severe refractory asthma: an international consensus statement from the Innovative Medicine Initiative (IMI). Thorax 2011; 66: 910-917.

43 Hafkamp-de Groen E, Lingsma HF, Caudri D, et al. Predicting asthma in preschool children with asthma-like symptoms: validating and updating the PIAMA risk score. J Allergy Clin Immunol 2013; 132: 1303-1310. 